\title{
A Method of Predicting the Shape and Scale of Rainfall-related Embankment Collapse
}

\author{
Tomoyasu SUGIYAMA, Dr. Eng. \\ Senior Researcher, Laboratory Head, \\ Geo-hazard \& Risk Mitigation Laboratory, Disaster Prevention Technology Division
}

Taiki MORI

West Japan Railway Company

\begin{abstract}
Osamu NUNOKAWA
Assistant Senior Researcher,

Naoyuki OTA, Dr. Eng.

Senior Researcher,

Geo-hazard \& Risk Mitigation Laboratory, Disaster Prevention Technology Division

Embankment collapse due to heavy rainfall along railway lines takes a variety of shapes and scales, which need to be predicted to determine effective measures for prevention. The results of such prediction also give information that is useful in estimating the amount of damage that will be caused to railway lines. Accordingly, we carried out statistical analysis of many past collapse examples and developed a method to predict the shape and scale of embankment failure. This report gives an outline of the method.
\end{abstract}

Keywords: rain, embankment, collapse shape, collapse scale, statistical method

\section{Introduction}

There are several types of rainfall-related embankment collapse in terms of shape and scale. However, such incidents do not uniformly cause train accidents, and some cases result only in slight damage. A way to predict the shape and scale of collapse is therefore necessary to enable the determination of effective countermeasures. We studied a risk evaluation model $[1,2,3]$ that determines priorities and methods for investment in disaster prevention for existing railway slopes. In order to calculate the risk of such failure, it is necessary to ascertain the cost of recovery from disasters and their influence on railroad operation etc. using the results obtained from prediction of the shape and scale of embankment and cut-slope collapse $[4,5]$. In order to satisfy these requirements, we carried out statistical analysis on previous data of embankment collapses. This paper reports a statistical method based on the analysis to predict the shape and scale of embankment collapse due to rainfall.

\section{Prediction method for the shape of collapse}

\subsection{Conditions of embankments and the shape of collapses}

Our study on a prediction method for the shape of collapse is founded on 66 previous cases [6] of embankment collapse. Table 1 shows the embankment conditions relating to the shape of collapse. We divided these 66 cases into two types as shown in Fig. 1 from the viewpoint of their influence on railroad operation. Type I is a small collapse within an embankment slope, which rarely causes problems in railroad operation. Type II is a large collapse involving the formation level, which causes serious dam-

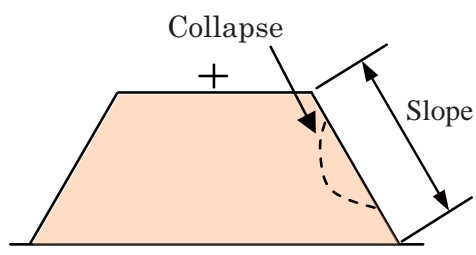

(a) Type I

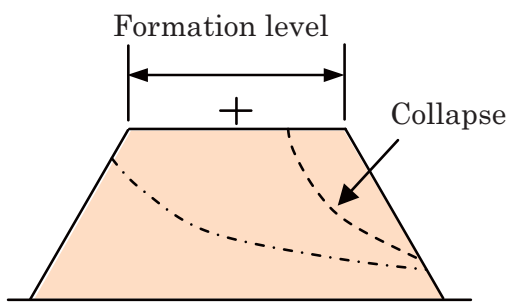

(b) Type II

Fig. 1 Shape of embankment collapse

age to trains and disrupts operation. Under this division, the data classification breaks down as 15 Type I cases and 51 Type II cases.

\subsection{Development of prediction method}

We developed a prediction method by carrying out analysis of quantification method II (referred to below as the analysis in Section 2). The analysis applied the shape of collapse as an objective variable and embankment conditions as explanatory variables. We first categorized embankment conditions (as shown in Table 1) and executed primary analysis to ascertain the relationship between the categorized conditions and the shape of collapse. We then extracted the conditions that dominate the shape of collapse through the primary analysis. Next, 
Table 1 Condition of the embankment

\begin{tabular}{|ll|}
\hline \multicolumn{2}{|c|}{ Condition of the embankment } \\
\hline (1) & Slope height of embankment $: h(\mathrm{~m})$ \\
\hline (2) & Length of embankment slope $: l(\mathrm{~m})$ \\
\hline (3) & Inclination of embankment slope $: \theta$ (degrees) \\
\hline (4) & Inclination of foundation ground : $\theta$ (degrees) \\
\hline (5) & Penetration resistance $: N c$ \\
\hline (6) & Soil (Sandy soil, Gravelly soil, Silty soil) \\
\hline (7) & Foundation ground (Alluvial, Diluvium, Rock) \\
\hline & Catchment condition (Non-catchment, Catchment (for \\
(8) & estimating side) , Catchment (for opposite estimating \\
\hline & side) ) \\
\hline (9) & $\begin{array}{l}\text { Longitudinal section type (Flat or single grade, Bound- } \\
\text { ary of cut and bank, Changing point of V-shape grade) }\end{array}$ \\
\hline (10) & $\begin{array}{l}\text { Cross-section type (Pure embankment, Half-cut and half- } \\
\text { bank, Widened bank) }\end{array}$ \\
\hline (11) & Protection (No protection, protection) \\
\hline (12) & Coefficient permeability $k$ (cm/s) \\
\hline
\end{tabular}

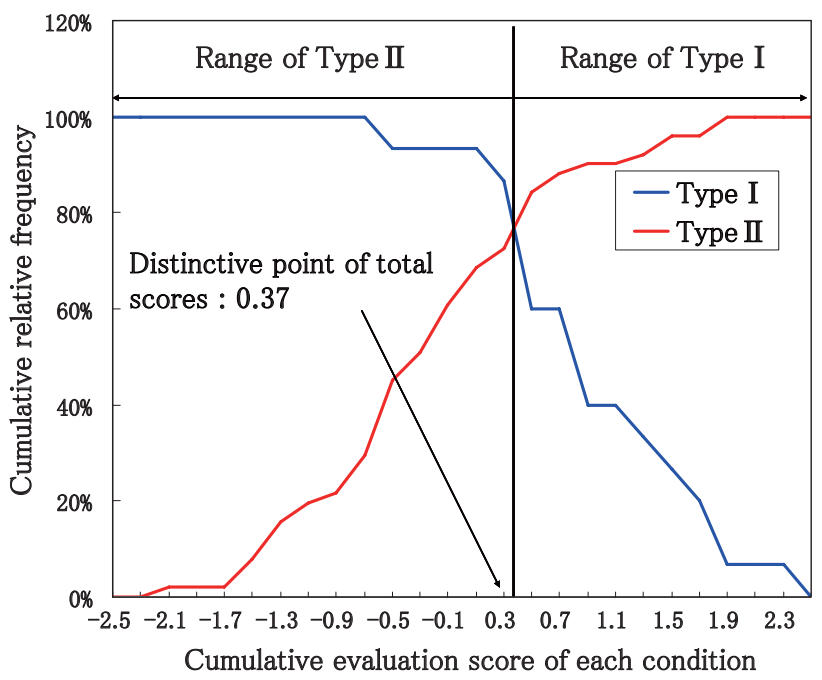

Fig. 2 Discriminant histogram

Table 2 Results of second analysis (collapse shape)

\begin{tabular}{|c|c|c|c|}
\hline Condition & Category & Score & Range of score \\
\hline \multirow{2}{*}{$\begin{array}{l}\text { Height of embankment slope } \\
h(\mathrm{~m})\end{array}$} & $h<10$ & -0.14 & \multirow{2}{*}{0.86} \\
\hline & $10 \leqq h$ & 0.72 & \\
\hline \multirow{2}{*}{$\begin{array}{l}\text { Inclination of embankment slope } \\
\theta \text { (degree) }\end{array}$} & $\theta<45$ & 0.15 & \multirow{2}{*}{1.11} \\
\hline & $45 \leqq \theta$ & -0.96 & \\
\hline \multirow{3}{*}{$\begin{array}{l}\text { Penetration resistance } \\
N c\end{array}$} & $N c<5$ & 0.21 & \multirow{3}{*}{0.86} \\
\hline & $5 \leqq N c<10$ & -0.23 & \\
\hline & $10 \leqq N c$ & -0.64 & \\
\hline \multirow[t]{2}{*}{ Soil } & Sandy soil & 0.18 & \multirow{2}{*}{0.60} \\
\hline & Gravelly soil $\cdot$ Silty soil & -0.42 & \\
\hline \multirow[t]{2}{*}{ Foundation ground } & Alluvial $\cdot$ Diluvium & -0.11 & \multirow{2}{*}{0.44} \\
\hline & Rock & 0.33 & \\
\hline \multirow[t]{3}{*}{ Catchment condition } & Non-catchment & 0.22 & \multirow{3}{*}{2.22} \\
\hline & Catchment (for estimating side) & -2.00 & \\
\hline & Catchment (for opposite estimating side) & -0.44 & \\
\hline \multirow[t]{2}{*}{ Longitudinal section type } & \begin{tabular}{|l|} 
Flat or single grade \\
\end{tabular} & 0.32 & \multirow[b]{2}{*}{0.87} \\
\hline & $\begin{array}{l}\text { Boundary of cut and bank } \cdot \text { Changing } \\
\text { point of V-shape grade }\end{array}$ & -0.55 & \\
\hline \multirow[t]{2}{*}{ Traversal section type } & Pure embankment & -0.37 & \multirow{2}{*}{0.69} \\
\hline & Half-cut and half-bank $\cdot$ Widened bank & 0.31 & \\
\hline \multirow{3}{*}{$\begin{array}{l}\text { Coefficient permeability } \\
k(\mathrm{~cm} / \mathrm{s})\end{array}$} & $k<10^{-4}$ & 0.30 & \multirow{3}{*}{1.53} \\
\hline & $10^{-4} \leqq k<10^{-2}$ & 0.10 & \\
\hline & $10^{-2} \leqq k$ & -1.22 & \\
\hline
\end{tabular}

collapse is expected. The second and third most influential extracted conditions are the coefficient permeability and the inclination of the embankment slope. Figure 2 is a distinction graph showing the results of the above analyses. As the figure indicates, the distinctive point of the total scores dividing embankments into Type I and Type II is 0.37 , and this value was therefore introduced as the discriminating median. In other words, embankments with total scores of more than 0.37 in each category are classified as Type I, and those with scores under 0.37 are classified as Type II.

\subsection{Application of the prediction method}

As outlined above, the discriminating median is 0.37 , and the discriminant equation is as follows:

$$
P=\Sigma-0.37
$$

where

we re-categorized the embankment conditions and executed secondary analysis. Table 2 shows the results of this secondary analysis: the extracted conditions, the category of classification, the scores for each category, and the range of scores. In this instance, higher scores in each classification category (for positive numbers) show a stronger tendency for prediction as Type I. In contrast, smaller scores (for negative numbers) show a stronger tendency for collapses to be Type II. The range of scores indicates the degree of influence on the shape of collapse. Table 2 indicates that the most influential extracted condition is the catchment condition. The scores of embankments with non-catchment in the vicinity were negative numbers, while those with catchment in the vicinity had positive scores. That is, embankments under catchment conditions have a strong tendency to be Type II, and large
$P$ : value for distinction

$\Sigma$ : sum total of scores in each classified category

In the case of $P>0$ or $P<0$, we can predict the embankment as Type I or Type II respectively. However, in order to apply the prediction to practical work, it is rational to adopt a new range in which the embankment is classified as either Type I or Type II as shown in Fig. 3. Equation (1) below shows the ratio of the number of Type I or Type II classifications against the total number of collapse data. In this case, it is also necessary to examine the transition of the ratio showing the number of predicted collapse-shape types to that for observed collapse-shape types. Equations (2) and (3) indicate each ratio $S$, with the suffix I or II representing each collapse-shape type. 
$T=b /(A+B) * 100(\%)$

$S_{\mathrm{I}}=(a+b) / \mathrm{A} * 100(\%)$

$S_{\text {II }}=(b+c) / \mathrm{A} * 100(\%)$

$T$ : ratio of the number classified as Type I or Type II against the total number of collapse data

$a$ : number of collapse data classified as Type I

$b$ : number of collapse data classified as either Type I or Type II

$c$ : number of collapse data classified as Type II

$A$ : observed number of Type I collapses

$B$ : observed number of Type II collapses

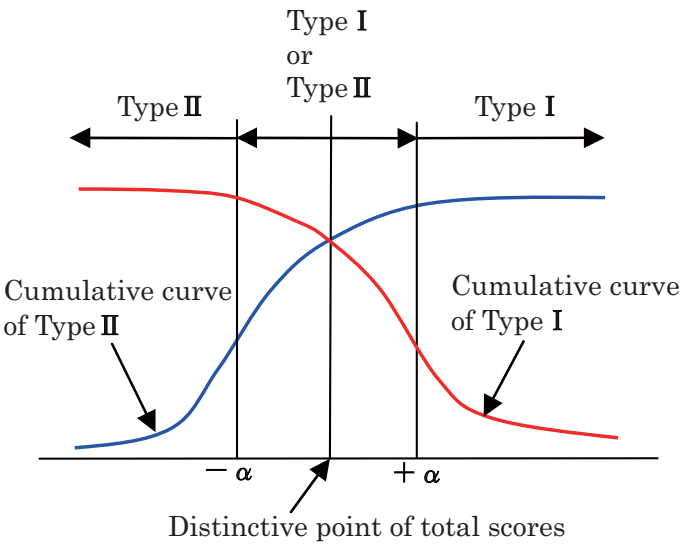

Fig. 3 Prediction range of collapse shape

Table 3 Rate of Type I or Type II and percentage of $\boldsymbol{S}$

\begin{tabular}{|c|c|c|c|c|c|c|}
\hline \multirow{2}{*}{} & \multicolumn{6}{|c|}{ Range of Type I or Type II $( \pm \alpha)$} \\
\cline { 2 - 7 } & 0 & \pm 0.1 & \pm 0.2 & \pm 0.3 & \pm 0.4 & \pm 0.5 \\
\hline$R$ & - & 15.2 & 18.2 & 22.7 & 27.3 & 38.9 \\
\hline$S_{1}$ & 73.3 & 86.7 & 86.7 & 93.3 & 93.3 & 93.3 \\
\hline$S_{\text {II }}$ & 80.4 & 84.3 & 88.2 & 88.2 & 90.2 & 90.2 \\
\hline
\end{tabular}

In this instance, we set six cases of $\alpha$ (as shown in Table 3 ): $0, \pm 0.1, \pm 0.2, \pm 0.3, \pm 0.4$ and \pm 0.5 , and then calculated $T, S_{\mathrm{I}}$ and $S_{\mathrm{II}}$ as shown in Table 3 . It is apparent that the wider the $\alpha$ becomes, the more $S_{\text {I }}$ and $S_{\text {II }}$ tend to increase. However, a rise in $T$ accompanies the increase in $S_{\text {I }}$ and $S_{\text {II }}$. The case of $\alpha= \pm 0.4$, in which the $S_{\text {I }}$ and $S_{\text {II }}$ values exceed $90 \%$ and $T$ falls below $30 \%$, was therefore introduced as a valid value. Accordingly, the discriminant equation is determined as shown below.

$$
P=\Sigma-0.37
$$

where

The case of $0.4<P$ : Type I

The case of $-0.4 \leqq P \leqq 0.4$ : either Type I or Type II

The case of $P<-0.4$ : Type II

\section{Prediction method for the scale of collapse}

\subsection{Outline of the method for predicting the scale of collapse}

In this section, we study a method of predicting the volume of collapsed soil, which represents the scale of an embankment collapse. We first classified the previous data into two shape types as outlined in Section 2. Next, we carried out analysis of quantification method I (referred to below as the analysis in Section 3) several times for those two groups. The following two methods of predicting the volume of collapsed soil were examined:

1) A prediction method using analysis based on the observed volume of collapsed soil obtained from past collapse data and the conditions of embankment collapse. The former values were applied as objective variables, and the latter as explanatory variables (referred to below as the direct prediction method).

2) A prediction method using analysis based on the observed value of collapse length, depth and width from past collapse data and the conditions of embankment collapse. The former values were applied as objective variables, and the latter as explanatory variables. First, the value of collapse length, depth and width are predicted through the analysis outlined above, and the volume of collapsed soil is then calculated using those predicted values (referred to below as the indirect prediction method).

The predicted scale of collapse (i.e. the volume of collapsed soil, collapse length, depth and width) obtained from the analysis is given by (5) as shown below.

$($ Predicted scale of collapse $)=\Sigma$ (certain scores corresponding to each embankment condition) + (constant)

where the scores corresponding to each embankment condition and the constant used are founded on the prediction standard outlined in the following sections.

In addition, the volume of collapsed soil in the indirect prediction method is calculated using (6).

$$
V=L^{*} T^{*} 1 / 2^{*} B
$$

where

$V$ : volume of collapsed soil

$L$ : collapse length (maximum length in the slope direction)

$T$ : collapse depth (maximum depth of collapsed block)

$B$ : collapse width (maximum width in the railway line direction)

We thus estimated the volume of collapsed soil by multiplying the cross section of collapse $\left(L^{*} T^{*} 1 / 2\right)$ by $B$, assuming that the volume of collapsed soil forms a triangular pillar.

\subsection{Prediction of the volume of collapsed soil in the case of Type I}

\subsubsection{The direct prediction method}

Table 4 shows the prediction standard obtained from the analysis for the case of Type I. The predicted volume of collapsed soil is calculated from the sum of each score corresponding to the height of the embankment, the inclination of the slope, the inclination of the basement and 
Table 4 Results of analysis ( $V$ )

\begin{tabular}{|c|c|c|c|}
\hline Condition & Category & Score & Range of score \\
\hline $\begin{array}{l}\text { Height of embankment slope } \\
h(\mathrm{~m})\end{array}$ & $\begin{array}{l}h<5 \\
5 \leqq h\end{array}$ & $\begin{array}{r}-113.5 \\
75.7 \\
\end{array}$ & 189.2 \\
\hline $\begin{array}{l}\text { Inclination of embankment slope } \\
\theta \text { (degree) }\end{array}$ & $\begin{array}{l}\theta<35 \\
35 \leqq \theta\end{array}$ & $\begin{array}{r}312.2 \\
-356.8 \\
\end{array}$ & 669.0 \\
\hline $\begin{array}{l}\text { Inclination of foundation ground } \\
\theta^{\prime} \text { (degree) }\end{array}$ & $\begin{array}{l}\theta^{\prime}<10 \\
\theta^{\prime} \geqq 10\end{array}$ & $\begin{array}{r}-216.5 \\
247.5 \\
\end{array}$ & 464.0 \\
\hline Cross-section type & $\begin{array}{l}\text { Pure embankment } \\
\text { Half-cut and half-bank } \\
\text { Widened bank }\end{array}$ & $\begin{array}{r}-116.7 \\
58.3\end{array}$ & 175.0 \\
\hline & Constant term & 165.0 & \\
\hline
\end{tabular}

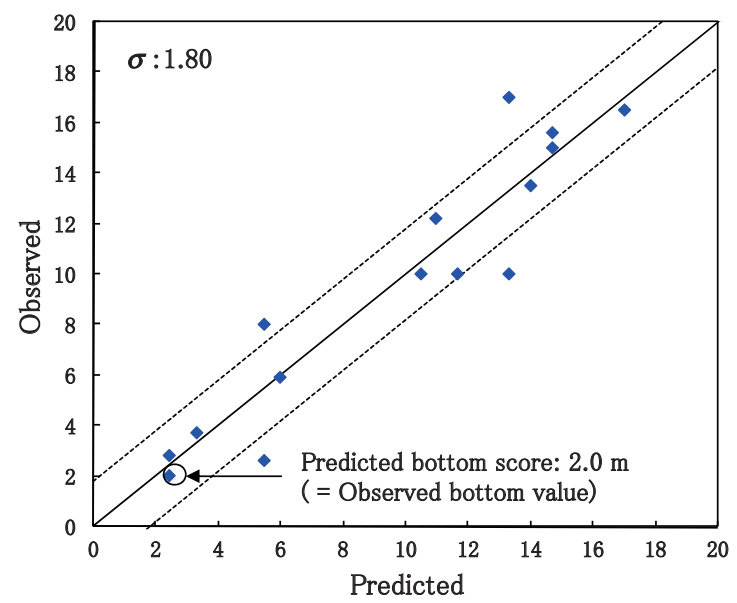

Table 5 Accuracy and divergence of analysis ( $V$ )

\begin{tabular}{|c|c|}
\hline & $V\left(\mathrm{~m}^{3}\right)$ \\
\hline$R^{2}$ & 0.71 \\
\hline$R$ & 0.84 \\
\hline Mean & 165.0 \\
\hline$\sigma$ of divergence & 163.1 \\
\hline
\end{tabular}

$R^{2}$ : Coefficient of determination

$R$ : Multiple correlation coefficient

$\sigma:$ Standard deviation

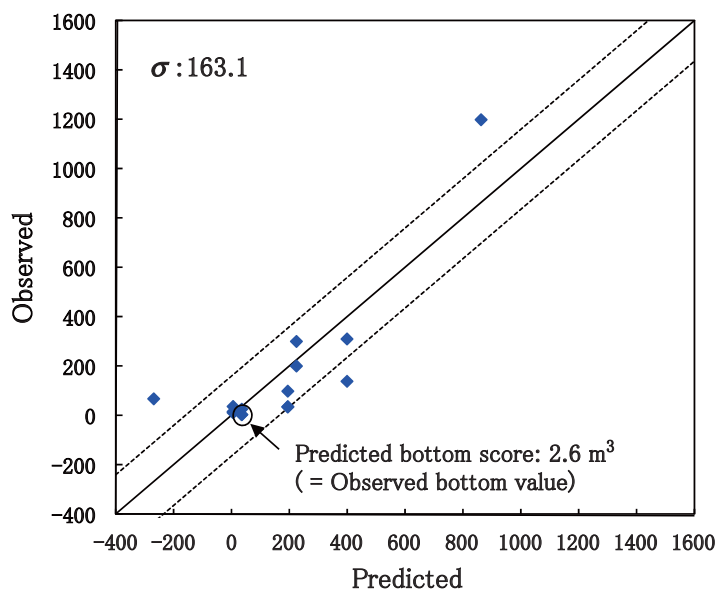

Fig. 4 Relationship between predicted score and observed value $(V)$

the cross-section form, as well as a constant. Table 5 shows the accuracy and divergence of the analysis, and Fig. 4 shows the relationship between the observed and predicted volumes of collapsed soil. Here, the term divergence refers to the difference between these two volumes. Despite a lack of accuracy in the analysis due to the scarcity of past data, it is possible to predict the volume of collapsed soil using the prediction standard (shown in Table 4). We also adopted $2.6 \mathrm{~m}^{3}$ (i.e., the minimum value of the observed volume) as the bottom line of the predicted volume as shown in Fig. 4.

\subsubsection{The indirect prediction method}

Tables 6,7 and 8 show the prediction standard for collapse length, depth and width respectively. Table 9 shows the accuracy and divergence of the analysis, and Figs. 5 to 7 indicate the relationship between the observed and predicted volumes of collapsed soil. In terms of the length and depth

Fig. 5 Relationship between predicted score and observed value $(L)$

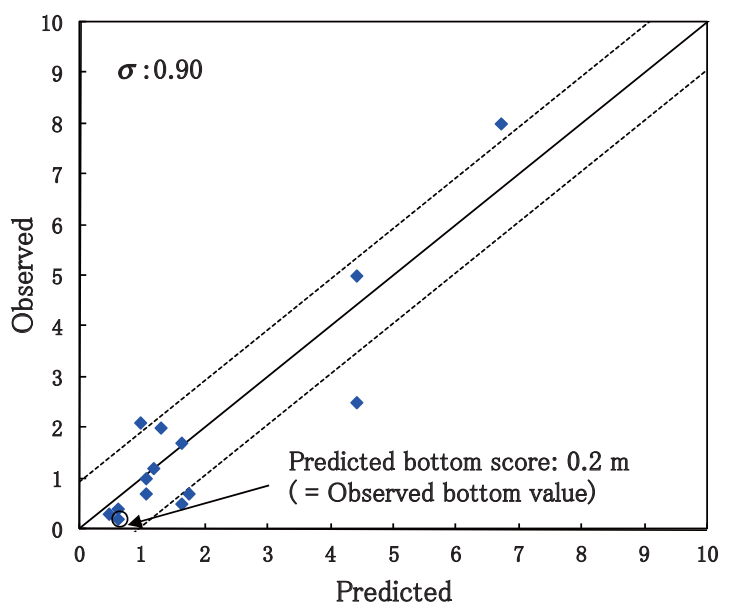

Fig. 6 Relationship between predicted score and observed value $(D)$

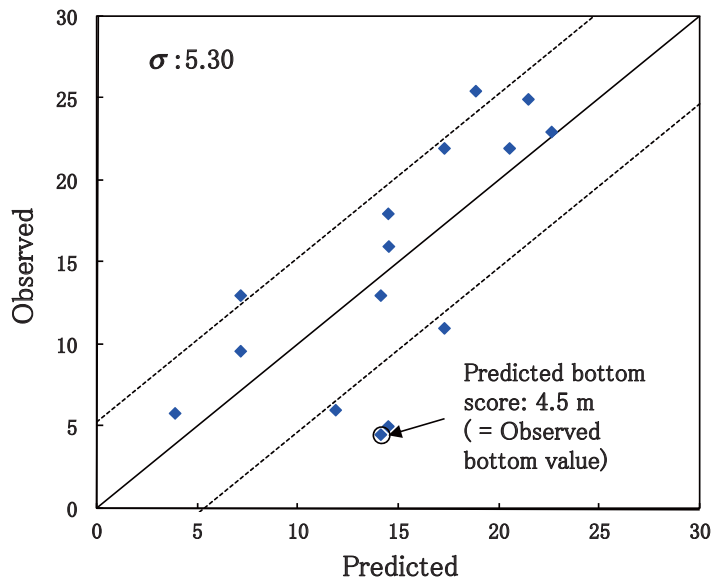

Fig. 7 Relationship between predicted score and observed value $(W)$

of collapse, the standard deviations of their divergence are $1.8 \mathrm{~m}$ and $0.9 \mathrm{~m}$ respectively, and the accuracy of the analysis is comparatively high. It is therefore supposed that the accuracy of the analysis is within the allowable limit. In the case of collapse width, the standard deviation of the divergence is greater than those for the length and depth of collapse, and the accuracy of the analysis is low. Neverthe- 
Table 6 Results of analysis ( $)$

\begin{tabular}{|c|c|c|c|}
\hline Condition & Category & Score & Range of score \\
\hline $\begin{array}{l}\text { Height of embankment slope } \\
h(\mathrm{~m})\end{array}$ & $\begin{array}{l}h<5 \\
5 \leqq h\end{array}$ & $\begin{array}{r}-5.11 \\
3.41 \\
\end{array}$ & 8.51 \\
\hline $\begin{array}{l}\text { Inclination of embankment slope } \\
\theta \text { (degree) }\end{array}$ & $\begin{array}{l}\theta<35 \\
35 \leqq \theta\end{array}$ & $\begin{array}{r}1.40 \\
-1.60\end{array}$ & 3.00 \\
\hline $\begin{array}{l}\text { Inclination of foundation ground } \\
\theta^{\prime} \text { (degree) }\end{array}$ & $\begin{array}{l}\theta^{\prime}<10 \\
\theta^{\prime} \geqq 10\end{array}$ & $\begin{array}{r}-1.64 \\
1.87\end{array}$ & 3.50 \\
\hline $\begin{array}{l}\text { Penetration resistance } \\
N c\end{array}$ & $\begin{array}{l}N c<5 \\
5 \leqq N c\end{array}$ & $\begin{array}{r}-0.23 \\
0.46\end{array}$ & 0.69 \\
\hline Foundation ground & $\begin{array}{l}\text { Alluvial } \\
\text { Diluvium } \cdot \text { Rock }\end{array}$ & $\begin{array}{r}-0.10 \\
0.09 \\
\end{array}$ & 0.19 \\
\hline Cross-section type & $\begin{array}{l}\text { Pure embankment } \\
\text { Half-cut and half-bank } \\
\text { Widened bank }\end{array}$ & $\begin{array}{r}-1.56 \\
0.78\end{array}$ & 2.34 \\
\hline & Constant term & 9.65 & \\
\hline
\end{tabular}

Table 7 Results of analysis (D)

\begin{tabular}{|c|c|c|c|}
\hline Condition & Category & Score & Range of score \\
\hline $\begin{array}{l}\text { Height of embankment slope } \\
h(\mathrm{~m})\end{array}$ & $\begin{array}{l}h<5 \\
5 \leqq h\end{array}$ & $\begin{array}{r}-0.41 \\
0.27\end{array}$ & 0.68 \\
\hline $\begin{array}{l}\text { Inclination of embankment slope } \\
\theta \text { (degree) }\end{array}$ & $\begin{array}{l}\theta<35 \\
35 \leqq \theta\end{array}$ & $\begin{array}{r}2.32 \\
-2.65\end{array}$ & 4.97 \\
\hline $\begin{array}{l}\text { Inclination of foundation ground } \\
\theta^{\prime} \text { (degree) }\end{array}$ & $\begin{array}{l}\theta^{\prime}<10 \\
\theta^{\prime} \geqq 10\end{array}$ & $\begin{array}{r}-1.09 \\
1.24\end{array}$ & 2.33 \\
\hline $\begin{array}{l}\text { Penetration resistance } \\
N c\end{array}$ & $\begin{array}{l}N c<5 \\
5 \leqq N c\end{array}$ & $\begin{array}{r}0.04 \\
-0.08\end{array}$ & 0.12 \\
\hline Foundation ground & $\begin{array}{l}\text { Alluvial } \\
\text { Diluvium } \cdot \text { Rock }\end{array}$ & $\begin{array}{r}0.01 \\
-0.01\end{array}$ & 0.03 \\
\hline Cross-section type & $\begin{array}{l}\text { Pure embankment } \\
\text { Half-cut and half-bank } \\
\text { Widened bank }\end{array}$ & $\begin{array}{r}-2.08 \\
1.04\end{array}$ & 3.12 \\
\hline & Constant term & 1.80 & \\
\hline
\end{tabular}

Table 8 Results of analysis ( $W$ )

\begin{tabular}{|c|c|c|c|}
\hline Condition & Category & Score & Range of score \\
\hline $\begin{array}{l}\text { Height of embankment slope } \\
h\end{array}$ & $\begin{array}{l}h<5 \\
5 \leqq h\end{array}$ & $\begin{array}{r}-2.83 \\
1.89\end{array}$ & 4.72 \\
\hline $\begin{array}{l}\text { Inclination of embankment slope } \\
\theta \text { (degree) }\end{array}$ & $\begin{array}{l}\theta<35 \\
35 \leqq \theta\end{array}$ & $\begin{array}{r}4.03 \\
-4.61\end{array}$ & 8.64 \\
\hline $\begin{array}{l}\text { Inclination of foundation ground } \\
\theta^{\prime} \text { (degree) }\end{array}$ & $\begin{array}{l}\theta^{\prime}<10 \\
\theta^{\prime} \geqq 10\end{array}$ & $\begin{array}{r}1.23 \\
-1.41 \\
\end{array}$ & 2.64 \\
\hline $\begin{array}{l}\text { Penetration resistance } \\
N c\end{array}$ & $\begin{array}{l}N c<5 \\
5 \leqq N c\end{array}$ & $\begin{array}{r}-0.87 \\
1.74\end{array}$ & 2.61 \\
\hline Foundation ground & $\begin{array}{l}\text { Alluvial } \\
\text { Diluvium } \cdot \text { Rock }\end{array}$ & $\begin{array}{r}-3.13 \\
2.74\end{array}$ & 5.87 \\
\hline Cross-section type & $\begin{array}{l}\text { Pure embankment } \\
\text { Half-cut and half-bank } \\
\text { Widened bank }\end{array}$ & $\begin{array}{r}1.04 \\
-0.52\end{array}$ & 1.56 \\
\hline & Constant term & 14.63 & \\
\hline
\end{tabular}

Table 9 Accuracy and divergence of analysis $(L, D, W$

\begin{tabular}{|c|c|c|c|}
\hline & $L(\mathrm{~m})$ & $D(\mathrm{~m})$ & $W(\mathrm{~m})$ \\
\hline$R^{2}$ & 0.88 & 0.81 & 0.51 \\
\hline$R$ & 0.94 & 0.90 & 0.71 \\
\hline Mean & 9.70 & 1.80 & 14.60 \\
\hline$\sigma$ of divergence & 1.80 & 0.90 & 5.30 \\
\hline
\end{tabular}

tion, we adopted $2.0 \mathrm{~m}$ (i.e., the minimum value of the observed collapse length) as the bottom line of the predicted collapse length as shown in Fig. 5. Similarly, the bottom lines for collapse depth and width are assumed to be $0.2 \mathrm{~m}$ and $4.5 \mathrm{~m}$ respectively, as shown in Figs. 6 and 7.

3.3 Prediction of the volume of collapsed soil in the case of Type II

less, it is possible to say that the collapse width can be predicted using this method. That is, in the case of Type I, it is possible to predict the collapse length, depth and width using the prediction standards; based on these, we can calculate the volume of collapsed soil using (6). In addi-
Table 10 shows the prediction standard obtained from

\subsubsection{The direct prediction method}


Table 10 Results of analysis ( $V$ )

\begin{tabular}{|c|c|c|c|}
\hline Condition & Category & Score & Range of score \\
\hline $\begin{array}{l}\text { Height of embankment slope } \\
h(\mathrm{~m})\end{array}$ & $\begin{array}{l}h<5 \\
5 \leqq h<10 \\
10 \leqq h\end{array}$ & $\begin{array}{r}-190.2 \\
51.0 \\
515.9 \\
\end{array}$ & 706.1 \\
\hline $\begin{array}{l}\text { Inclination of embankment slope } \\
\theta \text { (degree) }\end{array}$ & $\begin{array}{l}\theta<35 \\
35 \leqq \theta\end{array}$ & $\begin{array}{r}61.2 \\
-88.8 \\
\end{array}$ & 150.1 \\
\hline $\begin{array}{l}\text { Inclination of foundation ground } \\
\theta^{\prime} \text { (degree) }\end{array}$ & $\begin{array}{l}\theta^{\prime}<10 \\
\theta^{\prime} \geqq 10\end{array}$ & $\begin{array}{r}-134.8 \\
165.4 \\
\end{array}$ & 300.2 \\
\hline $\begin{array}{l}\text { Penetration resistance } \\
N c\end{array}$ & $\begin{array}{l}N c<5 \\
5 \leqq N c\end{array}$ & $\begin{array}{r}28.6 \\
-38.1 \\
\end{array}$ & 66.7 \\
\hline Soil & $\begin{array}{l}\text { Sandy soil } \cdot \text { Gravelly soil } \\
\text { Silty soil }\end{array}$ & $\begin{array}{l}-22.6 \\
198.6\end{array}$ & 221.2 \\
\hline Catchment condition & $\begin{array}{l}\text { Non-catchment } \\
\text { Catchment (for estimating } \\
\text { side) } \cdot \text { Catchment (for } \\
\text { opposite estimating side) }\end{array}$ & -3.4 & 15.3 \\
\hline Longitudinal section type & $\begin{array}{l}\text { Flat or single grade } \\
\text { Boundary of cut and bank } \\
\cdot \text { Changing point of } \mathrm{V}-\end{array}$ & $\begin{array}{r}3.9 \\
-6.2\end{array}$ & 10.0 \\
\hline \multirow[t]{2}{*}{ Cross-section type } & $\begin{array}{l}\text { Pure embankment } \\
\text { Half-cut and half-bank } \\
\text { Widened bank }\end{array}$ & $\begin{array}{r}146.2 \\
-129.3\end{array}$ & 275.6 \\
\hline & Constant term & 285.9 & \\
\hline
\end{tabular}

the analysis for the case of Type II. The predicted volume of collapsed soil is calculated from the sum of each score corresponding to the height of the embankment, the inclination of the slope, the inclination of the basement and the cross-section form, as well as a constant. Table 11 shows the accuracy and divergence of the analysis, and

Table 11 Accuracy and divergence of analysis ( $V$

\begin{tabular}{|c|c|}
\hline & $V\left(\mathrm{~m}^{3}\right)$ \\
\hline$R^{2}$ & 0.57 \\
\hline$R$ & 0.75 \\
\hline Mean & 285.9 \\
\hline$\sigma$ of divergence & 270.7 \\
\hline
\end{tabular}

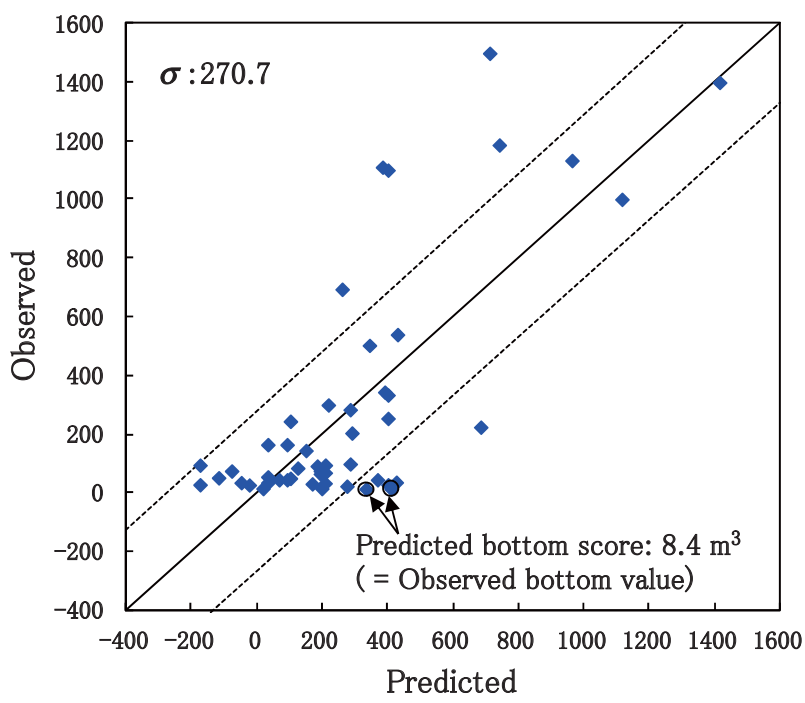

Fig. 8 Relationship between predicted score and observed value $(V)$
Fig. 8 shows the relationship between the observed and predicted volumes of collapsed soil. Although the accuracy of the analysis is not high, it is possible to predict the volume of collapsed soil. We adopted $8.4 \mathrm{~m} 3$ (i.e., the minimum value of the observed volume) as the bottom line of the predicted volume, as shown in Fig. 8.

\subsubsection{The indirect prediction method}

We examined the collapse length, depth and width by analysis, as in the case of Type I. Table 12 shows the accuracy and divergence of the analysis, and indicates that it is possible to predict the collapse length and depth. However, the accuracy of the analysis is poor for collapse width, and it is hard to predict a credible value using the prediction standards. Consequently, in the case of Type II, it is impossible to predict the volume of collapsed soil using (5).

Table 12 Accuracy and divergence of analysis $(L, D, W)$

\begin{tabular}{|c|c|c|c|}
\hline & $L(\mathrm{~m})$ & $D(\mathrm{~m})$ & $W(\mathrm{~m})$ \\
\hline$R^{2}$ & 0.67 & 0.43 & 0.12 \\
\hline$R$ & 0.82 & 0.65 & 0.42 \\
\hline Mean & 9.90 & 2.20 & 21.00 \\
\hline$\sigma$ of divergence & 5.00 & 1.10 & 13.90 \\
\hline
\end{tabular}

\subsection{Summary of prediction method for the scale of collapse}

On the basis of the examination explained in the above sections, Fig. 9 shows a flowchart from the stage of collapse shape classification to the stage of collapsed soil volume prediction. As the first step, collapse shapes are classified into three groups using (4): Type I $(0.4<P)$, 


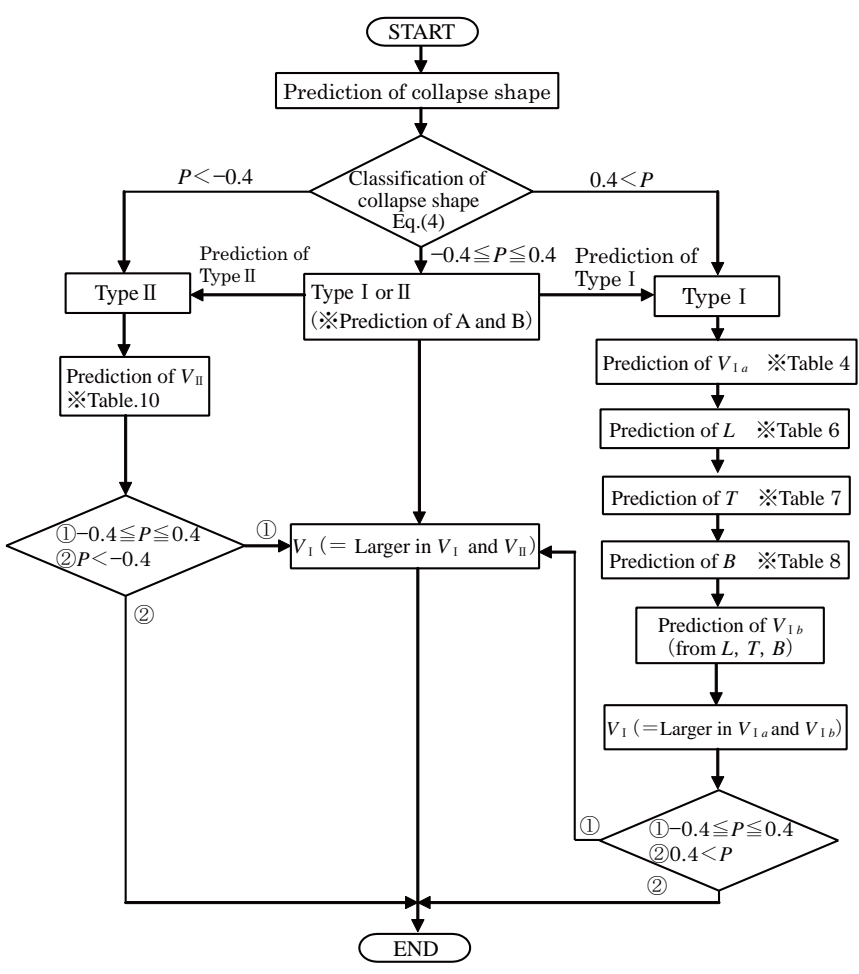

Fig. 9 Prediction flow of collapse shape and scale

Type II $(P<-0.4)$, and either Type I or Type II $(-0.4 \leqq P \leqq 0.4)$. In the case of Type I, we calculate the volume of collapsed soil, $V_{\mathrm{Ia}}$ and $V_{\mathrm{Ib}}$; the former is obtained using the direct prediction method and the latter from the indirect method, and the larger value is adopted as the predicted volume. In the case of Type II, we adopt the volume of collapsed soil $V_{\text {II }}$ obtained using the direct prediction method.

\section{Conclusion}

In this paper, we construct a method of predicting the shape and volume of collapsed soil through statistical analysis based on data from previous rainfall-related embankment collapses. As the next step, we plan to study damage to railways and railroad vehicles, influence on traffic control, retrieval costs etc., and to develop an appropriate model for methods and priorities of investment for disaster prevention on the basis of risk evaluation.

\section{References}

[1] Fuchiwaki, A., Mori, T., Nunokawa, O., Sugiyama, T., "A Method of Determining Disaster Prevention Measures for Existing Slopes along Railways Through Risk Evaluation," Autumn Reliability Symposium (2006), Reliability Engineering Association of Japan, Tokyo, Japan, October 20, 2006 (in Japanese).

[2] Fuchiwaki, A., Mori, T., Nunokawa, O., Sugiyama, T., "Consideration of Damage Probability Frequency Calculation for Disasters on Existing Slopes along Railways Through Risk Evaluation," Proceedings of the $62^{\text {nd }}$ JSCE Annual Meeting, JSCE, Hiroshima, Japan, September 12-15, 2007 (in Japanese).

[3] Mori, T., Fuchiwaki, A., Nunokawa, O., Sugiyama, T., "Trial Calculation of Damage Probability Frequency for Disasters on Existing Slopes along Railways Through Risk Evaluation," Proceedings of the $62^{\text {nd }} J S C E$ Annual Meeting, JSCE, Hiroshima, Japan, September 12-15, 2007 (in Japanese).

[4] Nunokawa, O., Sugiyama, T., Kobayashi, T., "Method to Predict the Scale of a Slope Collapse and the Impact Force of Soil," RTRI Report, Vol. 19, No. 10, pp.3338, 2005 (in Japanese).

[5] Nunokawa, O., Kobayashi, T., Sugiyama, T., Ota, N., Okada, K., "An Examination on Predicting the Scale of Surface Collapse in Cut Slopes," Proceedings of the $59^{\text {th }}$ JSCE Annual Meeting, JSCE, Aichi, Japan, September 8-10, 2004 (in Japanese).

[6] Sugiyama, T., "A Study on Disaster Risk Estimation for Prevention of Railway Slope Failure During Rainfall,” RTRI Report, Vol. 19, No. 5, pp.237, 1997 (in Japanese). 